\title{
Synthesis of IAN-type N,N-Ligands via Dynamic Kinetic Asymmetric Buchwald-Hartwig Amination
}

\author{
Pedro Ramírez-López, ${ }^{\S, \Sigma}$ Abel Ros, ${ }^{\S, \Sigma}$ Antonio Romero-Arenas, ${ }^{\S}$ Javier Iglesias-Sigüenza, ${ }^{\jmath}$ Rosario Fernández, ${ }^{*,}$ \\ José M. Lassaletta*, \\ ${ }^{\S}$ Instituto Investigaciones Químicas (CSIC-US), C/ Américo Vespucio, 49, 41092 Sevilla, Spain. \\ 'Departamento de Química Orgánica, C/ Prof. García González, 1, 41012 Sevilla, Spain
}

Supporting Information Placeholder

ABSTRACT: The $\mathrm{Pd}^{0}-$ catalyzed coupling of racemic heterobiaryl bromides, triflates or nonaflates with aryl/alkyl primary amines using QUINAP as the ligand provides the corresponding axially chiral heterobiaryl amines with excellent yields and enantioselectivities. Reactivity and structural studies of neutral and cationic oxidative addition intermediates support a dynamic kinetic asymmetric amination mechanism based on the labilization of the stereogenic axis in the latter, and suggest that coordination of the amine to the $\mathrm{Pd}$ center is the stereodetermining step.

In recent years, significant advances have been achieved in the field of asymmetric cross-coupling, in particular for the synthesis of axially chiral biaryls. ${ }^{1}$ In sharp contrast, the direct asymmetric heteroaryl-aryl cross-coupling remains as an unmet challenge, ${ }^{2}$ limiting the access to functionalized heterobiaryls with appealing structures for their use as ligands in asymmetric catalysis. As a remarkable example, the use Isoquinoline-Amino Naphthalene (IAN) and related derivatives, which can be seen as $\mathrm{N}\left(\mathrm{sp}^{2}\right), \mathrm{N}\left(\mathrm{sp}^{3}\right)$ analogues of QUINAP, have been scarcely investigated. ${ }^{3}$ A plausible explanation is the poor availability: there are no commercially available representatives and their synthesis still requires chromatographic separation of diastereomeric mixtures (Scheme 1, eq. 1), ${ }^{4}$ while the lack of a general and practical method of synthesis has also limited the structural diversity of known ligands of this type. Recently, we have reported a novel strategy for the synthesis of functionalized heterobiaryls based on dynamic kinetic asymmetric $\mathrm{C}-\mathrm{C}^{5}$ and $\mathrm{C}-$ $\mathrm{P}^{6}$ bond formations starting from heterobiaryl triflates to ensure the formations of cationic oxidative addition intermediates (Scheme 1, eq. 2). Stimulated by the growing potential of related axially chiral heterobidentate ligands, ${ }^{7}$ we decided to focus on the development of dynamic kinetic Buchwald-Hartwig (DYKAT: Dynamic Kinetic Asymmetric Transformation) amination of heterobiaryl electrophiles for the asymmetric synthesis of axially chiral IAN-type diamines (Scheme 1, eq. 3).

The unprecedented asymmetric amination of heterobiaryls is a particularly challenging goal due to the specific conditions required. First, a strong base is generally needed to achieve good reactivities, so that compatibility issues might arise with the hetero-
Scheme 1. Synthetic approaches to IAN amines

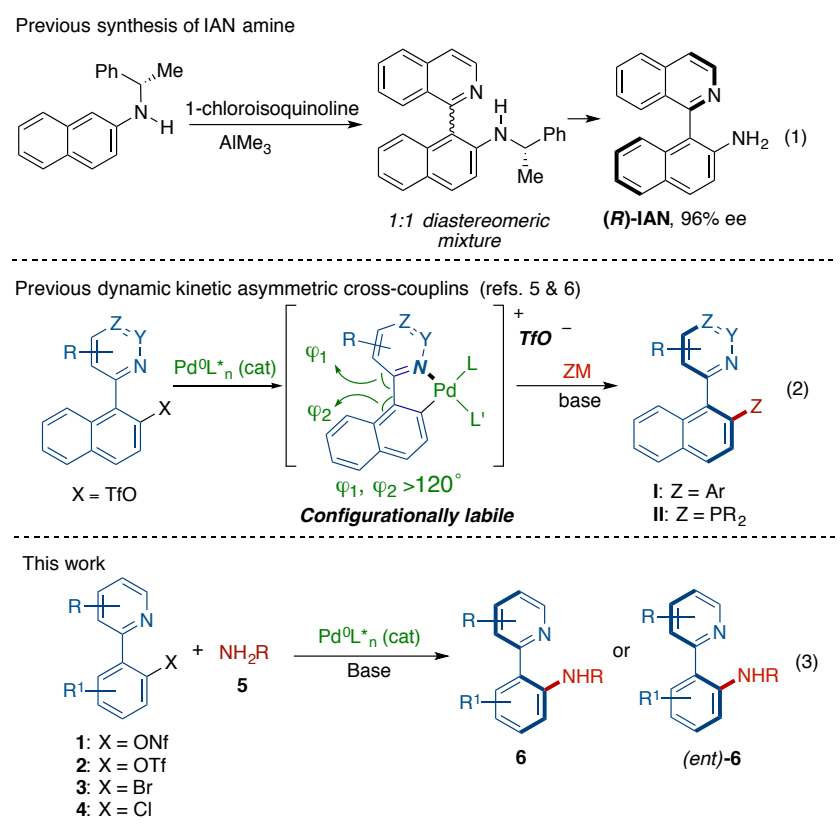

biaryl triflates used in previous DYKAT processes. Second, the racemization barriers for IAN amines are significantly lower than those of arylated products I or QUINAP-type products II, ${ }^{8}$ making necessary to work under exceptionally mild conditions. ${ }^{9}$ In order to minimize the hydrolysis of the starting material, we started using the coupling between nonaflate $( \pm)-\mathbf{1} \mathbf{A}^{10}$ and aniline $\mathbf{5} \mathbf{a}$ as a model reaction for the synthesis of IAN 6Aa, using $\mathrm{NaO} t \mathrm{Bu}$ as the base, dry toluene as the solvent at $60{ }^{\circ} \mathrm{C}$ and $10 \mathrm{~mol} \% \mathrm{Pd}(\mathrm{dba})_{2} / 12$ mol\% ligand as the catalyst system (Scheme 2 ).

Ligands that showed a good performance in related processes were selected for a preliminary screening: hydrazone-based ligands L1-L2, which provided good to excellent enantioselectivities in asymmetric Suzuki-Miyaura reactions, ${ }^{11}$ and TADDOL-derived phosphoramidites L3, which exhibited an excellent behavior in dynamic kinetic Suzuki-Miyaura couplings, ${ }^{5}$ showed a poor activity and only in the case of ligand $\mathbf{L 2}$ a relatively high enantiomeric excess $(72 \%$ ee) was observed. Similarly, ferrocene-based ligands L4-L5, previously used in C-P coupling reactions, ${ }^{6}$ or 
Scheme 2. Ligand Screening. ${ }^{a}$

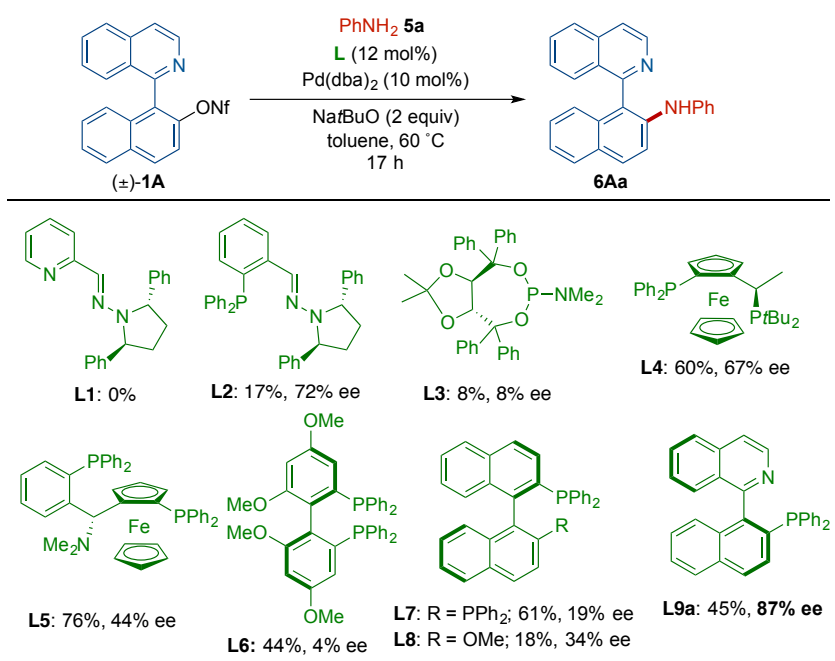

${ }^{\text {a }}$ Reactions conditions: $0.1 \mathrm{mmol} \mathbf{1 A}$ in toluene $(2 \mathrm{~mL}), 2$ equiv. of 5a, 2 equiv. of $\mathrm{NaO} t \mathrm{Bu}$. Ee's were determined by chiral HPLC analysis. See the Supporting Information for a more comprehensive screening.

commercially available axially chiral $\mathrm{P}, \mathrm{P}$ and $\mathrm{P}, \mathrm{O}$-ligands such as L6-L8 afforded moderate yields (18-76\%) and variable enantioselectivities (4-67\% ee). Taking into account the poor results provided by the atropo P,N-ligand QUINAP L9a in dynamic kinetic C-P bond formation, ${ }^{6 a}$ it was rather surprising to see the high level of enantioselectivity ( $87 \%$ ee) observed in this case, although partial hydrolysis of the starting $( \pm)-\mathbf{1 A}$ resulted in an unsatisfactory $45 \%$ yield. This undesired hydrolysis, however, could be avoided in two ways. First, it was possible to use a less nucleophilic base such as $\mathrm{Cs}_{2} \mathrm{CO}_{3}$, and the desired diamine (R)-6Aa was obtained in near quantitative yields while maintaining the level of enantioselectivity (Table 1 , entry 1 ). At $50{ }^{\circ} \mathrm{C}$, these mild conditions could also be applied to the amination of triflate $( \pm)-\mathbf{2 A}$ with a slightly lower yield (entry 2). Second, we speculated whether 1-(2bromonaphthalen-1-yl)isoquinoline ( \pm )-3A could also be a suitable substrate in this reaction. Although this material afforded disappointing results in dynamic kinetic asymmetric Suzuki coupling, ${ }^{5}$ the reaction of $( \pm)-\mathbf{3 A}$ with aniline 5a using $\mathrm{NaO} t \mathrm{Bu}$ as the base under the above conditions afforded the desired product $(R)-6 \mathbf{A a}$ in $95 \%$ yield with $89 \%$ ee in a shorter reaction time (17h, entry 3 ). The reactions of $( \pm)-\mathbf{1 A},( \pm)-\mathbf{3 A}$ and even chloride $( \pm)-\mathbf{4 A}$ could also be performed at $50{ }^{\circ} \mathrm{C}$, leading to slightly better enantioselectivities (entries 4-6). Other QUINAP and QUINAZOLINAP-type ligands L9b-g containing modified diaryl and dialkyl phosphino groups ${ }^{6 \mathrm{a}}$ were also tested in the model reaction but, unfortunately, none of them led to improved enantioselectivities (entries 7-12). Racemization studies performed with a toluene solution of $6 \mathrm{Aa}$ at 60,80 and $100^{\circ} \mathrm{C}$ showed that, after $48 \mathrm{~h}$, the product is configurationally stable at $60{ }^{\circ} \mathrm{C}$, but slowly racemizes at $80^{\circ} \mathrm{C}$ and above.

With the optimized conditions (entry 5) at hand, the scope of the methodology was explored using different bromides $( \pm)-3 \mathbf{A}-\mathbf{C}$ and amines 5a-m (Table 2). The reaction of bromide ( \pm )-3A (Series A) and arylamines 5a-c and 5g-h worked well at $50{ }^{\circ} \mathrm{C}$, affording the coupling products 6Aa-c and 6Ag-h with excellent yields and $90-96 \%$ ee in acceptable reaction times ( $\sim 25$ hours). Sterically hindered and electron-poor amines $\mathbf{5 d - f}$ and $\mathbf{5 h}-\mathbf{j}$ required longer reaction times $(30-48 \mathrm{~h})$, and a higher reaction
Table 1. Optimization. ${ }^{a}$

\begin{tabular}{|c|c|c|c|c|c|c|}
\hline \multirow[t]{2}{*}{$\begin{array}{l}( \pm)-1 A \\
( \pm)-2 A \\
( \pm)-3 A \\
( \pm-4 A\end{array}$} & $\begin{array}{l}\text { XaNf } \\
x=\text { OTf } \\
x=B r \\
x=C l\end{array}$ & $\begin{array}{l}\mathrm{NH}_{2} \mathbf{5 a} \\
12 \mathrm{~mol} \%) \\
)_{2}(10 \mathrm{~mol} \%) \\
2 \text { (2 equiv) } \\
22 \mathrm{~h}\end{array}$ & $6 \mathrm{Aa}$ & $\begin{array}{c}(S) \text {-L9b } \\
(S) \text {-L9c } \\
(S) \text {-L9d } \\
(R) \text {-L9e } \\
(R) \text {-L9f: } \\
(S) \text {-L9g }\end{array}$ & $\begin{array}{l}=\mathrm{C}, \mathrm{R}=(p-\mathrm{ON} \\
=\mathrm{C}, \mathrm{R}=(p-\mathrm{Me} \\
=\mathrm{C}, \mathrm{R}=(p-\mathrm{F}-\mathrm{C} \\
=\mathrm{C}, \mathrm{R}=\mathrm{Bu}, \\
\mathrm{C}, \mathrm{R}=\mathrm{Cy} \\
=\mathrm{N}, \mathrm{R}=\mathrm{Ph}\end{array}$ & $\begin{array}{l}\left.\mathrm{C}_{6} \mathrm{H}_{4}\right) \\
\left.\mathrm{H}_{4}\right) \\
\left.{ }_{4}\right)\end{array}$ \\
\hline & Substrate & Base & $\mathrm{T}\left({ }^{\circ} \mathrm{C}\right)$ & $\mathbf{L}$ & Yld. (\%) & $\mathrm{ee}^{\mathrm{b}}$ \\
\hline 1 & $( \pm)-1 \mathrm{~A}$ & $\mathrm{Cs}_{2} \mathrm{CO}_{3}$ & 60 & $(S)-\mathbf{L 9} \mathbf{a}$ & 99 & 88 \\
\hline $2^{c}$ & $( \pm)-2 A$ & $\mathrm{Cs}_{2} \mathrm{CO}_{3}$ & 50 & $(S)-\mathbf{L} \mathbf{9} \mathbf{a}$ & 81 & 92 \\
\hline $3^{d}$ & $( \pm)-3 A$ & $\mathrm{NaO} t \mathrm{Bu}$ & 60 & $(S)-\mathbf{L 9} \mathbf{a}$ & 95 & 89 \\
\hline 4 & $( \pm)-1 \mathrm{~A}$ & $\mathrm{Cs}_{2} \mathrm{CO}_{3}$ & 50 & $(S)-\mathbf{L 9 a}$ & 84 & 90 \\
\hline 5 & $( \pm)-\mathbf{3 A}$ & $\mathrm{NaO} t \mathrm{Bu}$ & 50 & $(S)-\mathbf{L 9} \mathbf{a}$ & 90 & 91 \\
\hline 6 & $( \pm)-4 A$ & $\mathrm{NaO} t \mathrm{Bu}$ & 50 & $(S)-\mathbf{L 9} \mathbf{a}$ & 92 & 89 \\
\hline 7 & $( \pm)-3 A$ & $\mathrm{NaO} t \mathrm{Bu}$ & 60 & $(S)-\mathbf{L} \mathbf{9} \mathbf{b}^{\mathrm{f}}$ & 99 & 84 \\
\hline 8 & $( \pm)-3 A$ & $\mathrm{NaO} t \mathrm{Bu}$ & 60 & $(S)-\mathbf{L} 9 \mathbf{c}^{\mathrm{g}}$ & 98 & 77 \\
\hline 9 & $( \pm)-3 A$ & $\mathrm{NaO} t \mathrm{Bu}$ & 60 & $(S)-\mathbf{L 9 d}$ & 98 & 61 \\
\hline 10 & $( \pm)-\mathbf{3 A}$ & $\mathrm{NaO} t \mathrm{Bu}$ & 60 & $(R)-\mathbf{L 9 e}$ & 26 & 50 \\
\hline 11 & $( \pm)-3 A$ & $\mathrm{NaO} t \mathrm{Bu}$ & 60 & $(R)-\mathbf{L 9 f}$ & 77 & 68 \\
\hline 12 & $( \pm)-3 A$ & $\mathrm{NaO} t \mathrm{Bu}$ & 60 & $(S)-\mathbf{L} 9 \mathbf{g}^{\mathrm{h}}$ & 78 & 20 \\
\hline
\end{tabular}

${ }^{\text {a }}$ Reactions conditions: $0.1 \mathrm{mmol}$ scale in toluene $(2 \mathrm{~mL}), 2$ equiv. of 5a, 2 equiv. of base. ${ }^{b}$ Determined by chiral HPLC analysis. ${ }^{c} t: 48 \mathrm{~h} .{ }^{\mathrm{d}} t$ : 17h. ${ }^{\text {f }} 98 \%$ ee. ${ }^{\mathrm{g}} 96 \%$ ee. ${ }^{\mathrm{h}} 99 \%$ ee.

temperature of $60^{\circ} \mathrm{C}$ was also needed for the latter, but in all cases the corresponding products 6 were obtained in good yields and enantioselectivities ( $88-93 \%$ ee). Interestingly, $p$-chloro- and $p$ bromo-anilines 5e and $\mathbf{5 f}$ are suitable substrates, highlighting the higher relative reactivity of the heterobiaryl bromide, which can be attributed to the directing effect by the isoquinoline $\mathrm{N}$ atom. Aliphatic amines 5k-m could also be coupled using 4-10 equiv. of amine and 4 equiv. of $\mathrm{NaO} t \mathrm{Bu}$ to give the desired products $(R)$ 6Ak-m in good to excellent yields (61-86\%) and $86-91 \%$ ee after 72 hours at $60{ }^{\circ} \mathrm{C}$. Bromide $( \pm)-3 \mathrm{~B}$ showed similar reactivity patterns and the desired diamines $6 \mathbf{B a}-\mathbf{m}$ were obtained in good to excellent yields and $86-93 \%$ ee. Finally, bromide $( \pm)-3 \mathrm{C}$ was also used in atroposelective amination with anilines $\mathbf{5 a - d , g , j}$ to afford $\mathbf{C}$-series products. A higher reaction temperature $\left(60^{\circ} \mathrm{C}\right)$ and longer reaction time $(45 \mathrm{~h})$ were in general required, but good yields (72$98 \%$ ) and enantioselectivities (88-91\% ee) were also achieved. As a limitation, poor reactivity was observed when secondary amines were used as reagents.

Compounds $(R)-\mathbf{6 B f}$ and $(R)-6 \mathbf{B l}$ were obtained in enantiopure form ( $>99 \%$ ee) after crystallization. Additionally, X-ray analysis of the former was used to assign the absolute $R_{\mathrm{a}}$ configuration. Similarly, X-ray analysis of the cationic complex $\{\mathrm{Cu}(\mathrm{I})[(R)$ 6Aa $\left.]_{2}\right\}^{+} \mathrm{PF}_{6}{ }^{-}$was used to confirm the absolute $R$ configuration of (R)-6Aa. The absolute configuration of other products 6A-C was assigned by analogy assuming a uniform reaction pathway.

The free IAN amine $(R)-7$ could be obtained after Pd-catalyzed deprotection of allylamine $(R)-6$ Am using $N, N^{\prime}$-dimethylbarbituric 
Table 2. Dynamic Kinetic Asymmetric C-N Couplings: Scope. ${ }^{2}$
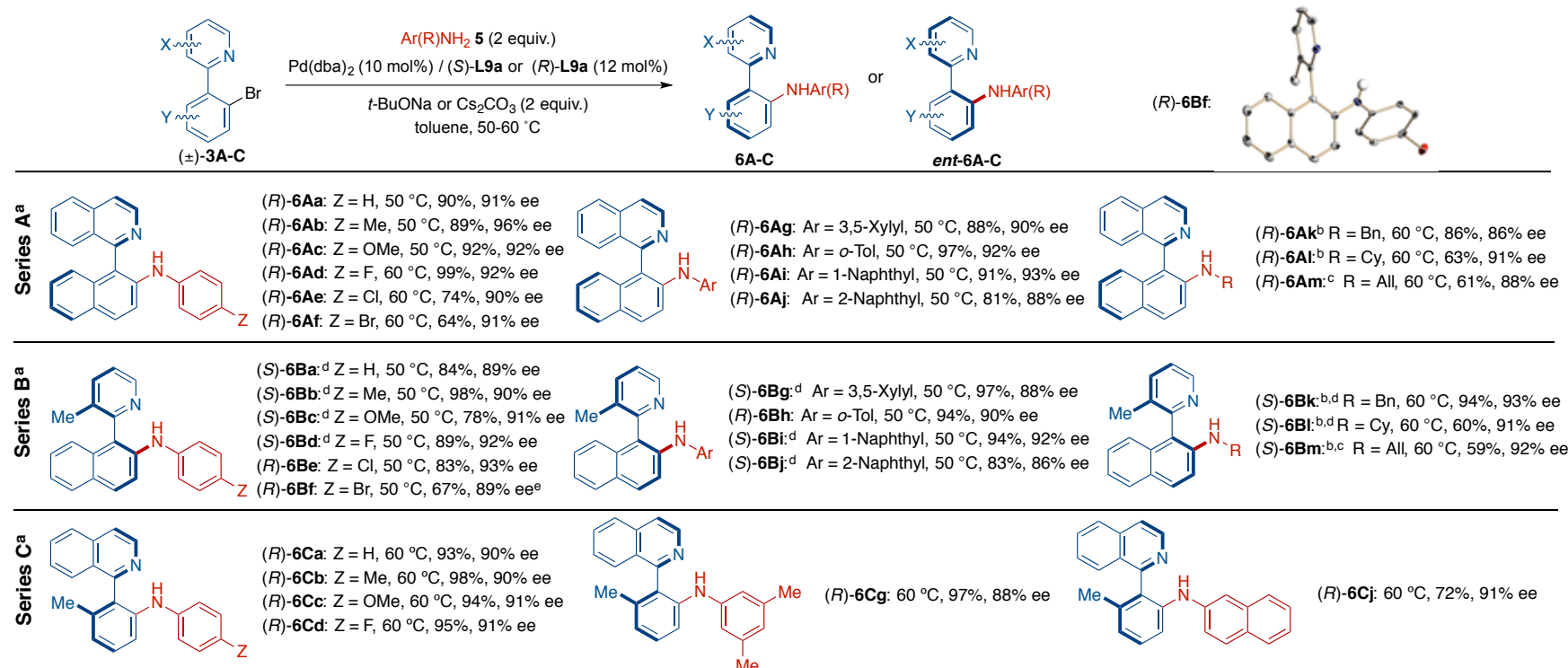

(R)-6Cj: $60{ }^{\circ} \mathrm{C}, 72 \%, 91 \%$ ee

${ }^{a}$ Reaction conditions: $0.1 \mathrm{mmol}$ scale in toluene $(2 \mathrm{~mL}), 2$ equiv. of $\mathbf{5}, 2$ equiv. of $\mathrm{NaO} \mathrm{BBu}, t: 22-48 \mathrm{~h}$ (see Supporting Information). ${ }^{\mathrm{b}} 4$ equiv. of $\mathrm{NaO} t \mathrm{Bu}$ and 4 equiv. of $\mathbf{5}$ were used. ${ }^{\mathrm{c}} 4$ equiv. of $\mathrm{NaO} t \mathrm{Bu}$ and 10 equiv. of $\mathbf{5}$ were used. ${ }^{\mathrm{d}}(R)$-L9a was used. ${ }^{\mathrm{e}}>99 \%$ ee after crystallization.

Scheme 3. Representative transformations.<smiles>C=CCNc1ccc2ccccc2c1-c1nccc2ccccc12</smiles>

(R)-6Am (IAN), $88 \%$ ee<smiles>c1ccc(Nc2ccc3ccccc3c2-c2nccc3ccccc23)cc1</smiles>

(R)-6Aa, 91

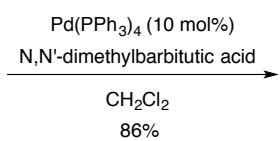

$86 \%$

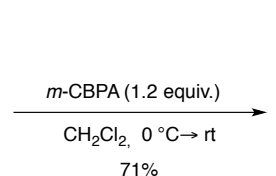

$71 \%$

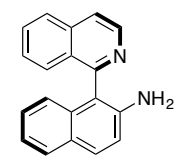

(R)-7A (IAN), 86\% ee

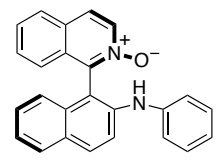

(R)-8Aa (IAN), 91\% ee acid as the reagent ${ }^{12}$ (Scheme 3). Additionally, products 6 are direct precursors of axially chiral $\mathrm{N}$-oxides ${ }^{7 \mathrm{~b}}$ by virtue of the selective $\mathrm{N}\left(\mathrm{sp}^{2}\right)$ oxidation performed with $m$-CPBA, as illustrated with the synthesis of $(R)-8$. Compared to the previously developed Suzuki coupling, ${ }^{5}$ the better performance of $( \pm)-\mathbf{3 A}$ can be explained for the different reaction conditions applied in this case. According to the mechanism depicted in Scheme 4, the base is believed to play a dual role, behaving also as an efficient bromide scavenger thanks to the low solubility of $\mathrm{NaBr}$ in toluene. In order to provide some support for this hypothesis, we tackled the isolation of the oxidative addition intermediates from heterobiaryl triflate ( \pm -2A and bromide $( \pm)-\mathbf{3 A}$. The equimolar reaction of the former with $(S)$-L9a and $[\mathrm{Pd}(\mathrm{Cp})($ allyl) $]$ afforded the cationic OA intermediate $\mathrm{OAI}^{+}(\mathbf{O T f})$ in $88 \%$ yield after crystallization (Scheme 5). The single-crystal X-ray diffraction analysis of this complex showed the expected five-membered, cationic palladacycle structure and confirmed that the angles $\varphi_{1}[\mathrm{C}(39)-\mathrm{C}(40)-\mathrm{C}(41)]$ and $\varphi_{2}[\mathrm{C}(40)-\mathrm{C}(41)-\mathrm{C}(42)]$ are significantly wider $\left(127.6^{\circ}\right.$ and $125.0^{\circ}$, respectively) than the ideal value of $120^{\circ}$. The structure reveals also a severe distortion of the square planar geometry at the $\mathrm{Pd}^{\mathrm{II}}$ center (torsion angle of $23.1^{\circ}$ between the P-Pd-N(1) and the $\mathrm{C}(50)-\mathrm{Pd}-\mathrm{N}(2)$ planes), with a $\mathrm{Pd}-\mathrm{N}(1)$ bond longer than the Pd$\mathrm{N}(2)$ one (2.141 $\AA$ and $2.098 \AA$, respectively), as a consequence of the stronger trans influence by the aryl ligand. This complex was
Scheme 4. Proposed amination mechanism.

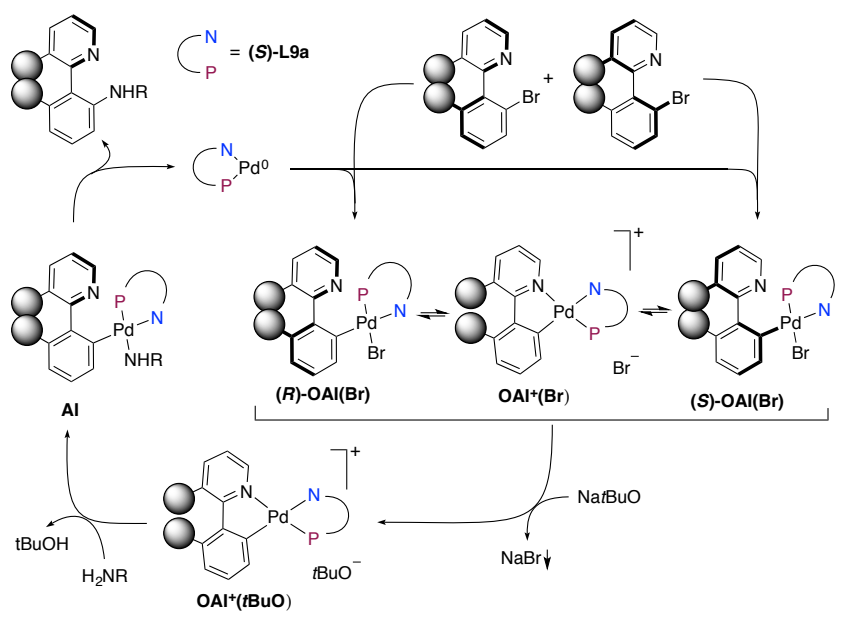

treated with aniline (20 equiv.) and $\mathrm{Cs}_{2} \mathrm{CO}_{3}$ (20 equiv.) to afford (R)-6Aa after $7 \mathrm{~h}$ at $50{ }^{\circ} \mathrm{C}$ in $57 \%$ yield and $74 \%$ ee. ${ }^{13}$ Although an apparent $\left(S_{a}\right)$ configuration is observed, we assume that the aforesaid widening of angles $\varphi_{1}$ and $\varphi_{2}$ results in a rapid interconversion of atropoisomers. ${ }^{14}$ In the same way, equimolar amounts of $(S)$ L9a, bromide $( \pm)-\mathbf{3 A}$, and $[\mathrm{Pd}(\mathrm{Cp})($ allyl $)]$ were made to react overnight at $80{ }^{\circ} \mathrm{C}$ in toluene; ${ }^{1} \mathrm{H}-\mathrm{NMR}$ and ${ }^{31} \mathrm{P}$ NMR analysis of the crude reaction mixture revealed a complex mixture ${ }^{15}$ in which signals assigned to the cationic $\mathrm{OA}$ intermediate $\mathbf{O A I}^{+}(\mathbf{B r})$ were identified. Stoichiometric reaction of this mixture with aniline quantitatively afforded the product $(R)-6$ Aa with $87 \%$ ee. Additionally, crystals of the neutral intermediate $(\boldsymbol{R})-\mathbf{O A I}(\mathbf{B r})$ suitable for X-ray diffraction analysis could be obtained from this mixture. In this complex, the bromine atom remains attached to the $\mathrm{Pd}$ center [Pd-Br bond length $2.491 \AA]$ and the isoquinoline and 2naphthyl rings are placed in a near perpendicular arrangement. It is assumed that the reaction of this mixture with the base results in a $\mathrm{Br}^{-}$to $t \mathrm{BuO}^{-}$ligand exchange facilitated by the low solubility of $\mathrm{NaBr}$ in toluene. Arguably, the poorer coordinating ability and 
Scheme 5. Synthesis and and X-ray structures of oxidative addition intermediates $\mathbf{I O A}^{+}(\mathbf{O T f})$ and (S)-IOA(Br).
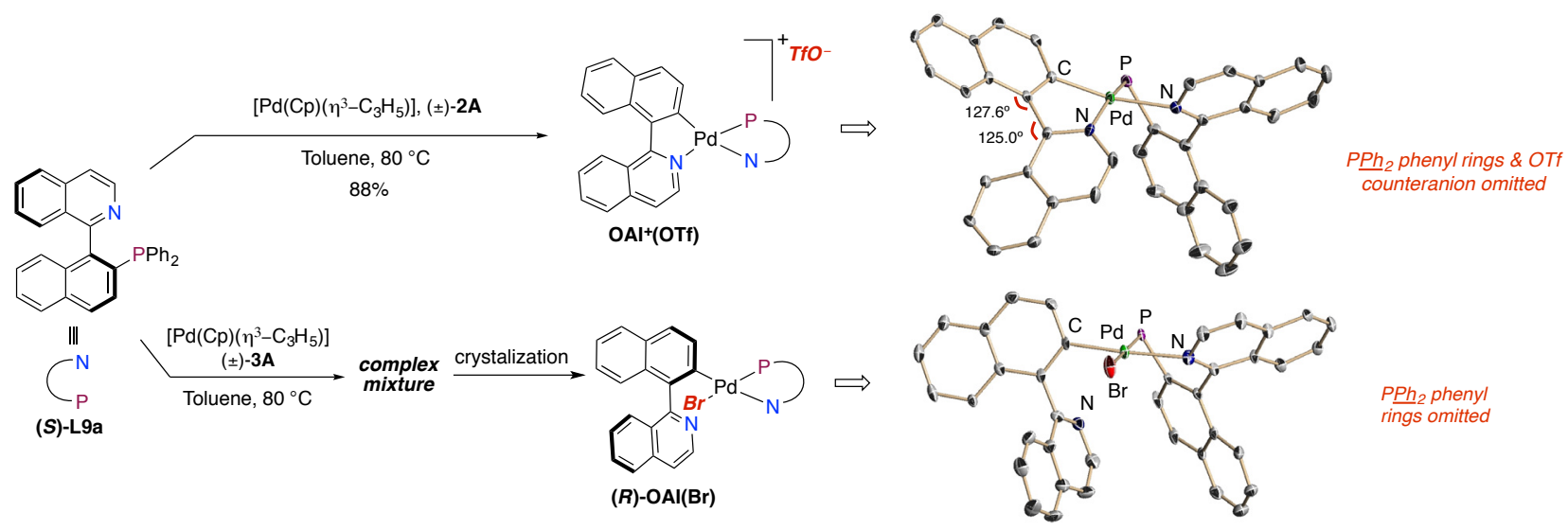

bigger size of the counteranion favors the formation of the cationic intermediate $\mathbf{O A I}^{+}(\mathbf{t} \mathbf{B u O})$, from which the coordination of the amine $\mathbf{5}$ generates the amination intermediate $\mathbf{A I}$ in the enantioselectivity determining step. It is worth noting that the structure of the proposed $\mathbf{O A I}^{+}(\mathbf{t} \mathbf{B u O})$ intermediate should closely mimic that of the isolated complex $\mathbf{I O A}^{+}(\mathbf{O T f})$, accounting for the similar stereochemical result through both intermediates.

In summary, we have developed a new and efficient procedure for the asymmetric synthesis of IAN-type N,N-ligands based on a dynamic kinetic asymmetric Buchwald-Hartwig amination of racemic heterobiaryl electrophiles. The use of QUINAP as the ligand allowed the isolation of the products in high yields and good to excellent enantioselectivities. The isolation of cationic and neutral oxidative addition intermediates supports a mechanism based in the labilization of the stereogenic axis in the former.

\section{ASSOCIATED CONTENT}

Supporting Information. Experimental procedures and characterization data for new compounds, crystallographic data for $(R)$ 6Bf, $\mathrm{OAI}^{+}(\mathrm{OTf})$ and (S)-OAI(Br), and HPLC traces for compounds 6, 7 and 8 . This material is available free of charge via the Internet at http://pubs.acs.org.

\section{AUTHOR INFORMATION}

\section{Corresponding Author}

ffernan@us.es,jmlassa@iiq.csic.es

\section{Author Contribution}

${ }^{\Sigma}$ P. R.-L. and A. R. contributed equally to this work.

\section{ACKNOWLEDGMENT}

We thank the Ministerio de Ciencia e Innovación (Grants CTQ2013-48164-C2-1-P and CTQ2013-48164-C2-2-P, contract RYC-2013-12585 for A.R.), European FEDER Funds, and Junta de Andalucía (Grant 2012/FQM 10787) for financial support.

\section{REFERENCES}

(1) Recent reviews: (a) Zhang, D.; Wang, Q. Coord. Chem. Rev., 2015, 286, 1. (b) Wencel-Delord, J.; Panossian, A.; Leroux, F. R.; Colobert, F. Chem. Soc. Rev. 2015, 44, 3418. (c) Pauline, L.; Manoury, E.; Poli, R.; Deydier, E.; Labande, A. Coord. Chem. Rev. 2016, 308, 131.
(2) Mosquera, A.; Pena, M. A.; Pérez Sestelo, J.; Sarandeses, L. A., Eur. J. Org. Chem. 2013, 2555.

(3) (a) Cortright, S. B.; Huffman, J. C.; Yoder, R. A.; Coalter, J. N.; Johnston, J. N. Organometallics 2004, 23, 2238. (b) Cortright, S. B.; Johnston, J. N. Angew. Chem., Int. Ed. 2002, 41, 345.

(4) Luesse, S. B.; Counceller, C. M.; Wilt, J. C.; Perkins, B. R.; Johnston, J. N. Org. Lett., 2008, 10, 2445.

(5) Ros, A.; Estepa, B.; Ramírez-López, P.; Álvarez, E.; Fernández, R.; Lassaletta, J. M. J. Am. Chem. Soc., 2013, 135, 15730.

(6) (a) Ramírez-López, P.; Ros, A.; Estepa, B.; Fernández, R.; Fiser, B.; Gómez-Bengoa, E.; Lassaletta, J. M. ACS Catal. 2016, 6, 3955. See also: (b) Bhat, V.; Wang, S.; Stoltz, B. M.; Virgil, S. C. J. Am. Chem. Soc., 2013, 135, 16829.

(7) (a) Fernández, E.; Guiry, P. J.; Connole, K. P. T.; Brown, J. M. J. Org. Chem. 2014, 79, 5391. and references cited therein; (b) Malkov, A. V.; Ramírez-López, P.; Biedermannová, L.; Rulíšek, L.; Dufková, L.; Kotora, M.; Zhu, F.; Kočvský. P. J. Am. Chem. Soc. 2008, 130, 5341; (d) Tanaka, S.; Seki, T.; Kitamura, M. Angew. Chem. Int. Ed. 2009, 48, 8948; (e) Francos, J.; Grande-Carmona, F.; Faustino, H.; Iglesias-Sigüenza, J.; Díez, E.; Alonso, I.; Fernández, R.; Lassaletta, J. M.; López, F.; Mascareñas, J. L. J. Am. Chem. Soc. 2012, 134, 14322. (f) Liu, Y. E.; Lu, Z.; Li, B.; Tian, J.; Liu, F.; Zhao, J.; Hou, C.; Li, Y.; Niu, L.; Zhao, B. J. Am. Chem. Soc. 2016, DOI: 10.1021/jacs.6b03930.

(8) Cortright, S. B.; Yoder, R. A.; Johnston, J. N. Heterocycles 2004, 62, 223.

(9) Paradies, J. In Metal-Catalyzed Cross- Coupling Reactions and More; de Meijere, A., Brase, S., Oestreich, M., Eds.; Wiley: Weinheim, 2014; Ch 13, pp 995-1060.

(10) Nonaflates (nonafluorobutanesulfonates) have been used as an alternative to triflates due to their higher stability and similar reactivity: Högermeier, J.; Reissig H.-U. Adv. Synth. Catal. 2009, 351, 2747.

(11) (a) Ros, A.; Estepa, B.; Bermejo, A.; Álvarez, E.; Fernández, R.; Lassaletta, J. M. J. Org. Chem. 2012, 77, 4740. (b) Bermejo, A.; Ros, A.; Fernández, R.; Lassaletta, J. M.; J. Am. Chem. Soc. 2008, 130, 15798.

(12) Garro-Helion, F.; Merzouk, A.; Guibé; F. J. Org. Chem. 1993, 58, 6109. Deallylation with polymethylhydrosiloxane $/ \mathrm{ZnCl}_{2} / \mathrm{Pd}\left(\mathrm{PPh}_{3}\right)_{4}$ (Chandrasekhar, S.; Reddy, C. R.; Rao, R. J. Tetrahedron 2001, 57, 3435) or $\mathrm{PhSO}_{2} \mathrm{Na} / \mathrm{CSA} / \mathrm{Pd}\left(\mathrm{PPh}_{3}\right)_{4}$ (Honda, M.; Morita, H.; Nagakura, I. J. Org. Chem. 1997, 62, 8932) afforded the product in racemic form, while catalytic hydrogenation $\left(\mathrm{H}_{2}, \mathrm{Pd} / \mathrm{C}\right)$ was uneffective.

(13) In spite of the evident strain in the structure of $\mathbf{O A I}^{+}(\mathbf{O T f})$, no reaction with aniline 5a (20 equiv.) was observed in the absence of $\mathrm{Cs}_{2} \mathrm{CO}_{3}$, even after heating at $70^{\circ} \mathrm{C}$ overnight.

(14) Variable temperature ${ }^{1} \mathrm{H}$ NMR $\left(25^{\circ} \mathrm{C} \rightarrow-78^{\circ} \mathrm{C}\right)$ spectrometry did not show a dynamic behavior, indicating that the barrier for the interconversion of atropoisomers is very low (see Supporting Information).

(15) We assume that the $\mathrm{C}(2)-\mathrm{Pd}$ bond in neutral intermediates $\mathbf{O A I}(\mathbf{B r})$ is a configurationally stable stereogenic axis and, therefore, four possible isomers can be formulated. 


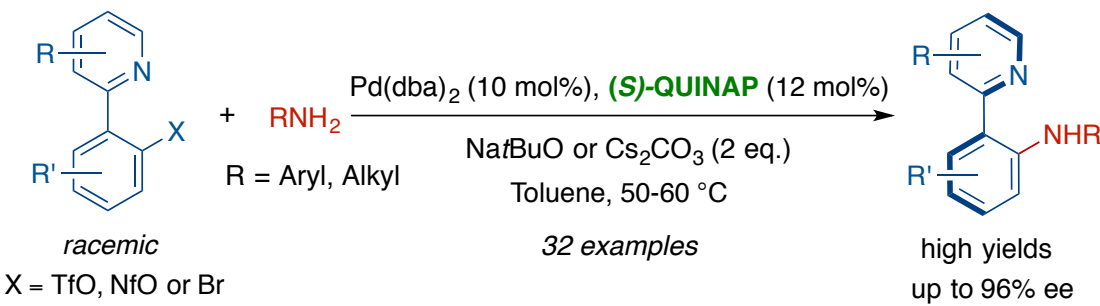

